\title{
Bone Tumors of the Hands: Focus on CT and MR Findings
}

Lee SJ ${ }^{1}$, Choo HJ ${ }^{1 *}$, Heo YJ ${ }^{1}$, Kim SW ${ }^{1}$, Cho $\mathrm{KH}^{2}$, Suh $\mathrm{KJ}^{3}$, Lee SM${ }^{4}$, Lee $\mathrm{YH}^{5}$, Lee $\mathrm{IS}^{6}$ and $\mathrm{Yi} \mathrm{J} \mathrm{H}^{7}$

${ }^{1}$ Department of Radiology, Inje University Busan Paik Hospital, South Korea

${ }^{2}$ Department of Radiology, Youngnam University Medical Center, South Korea

${ }^{3}$ Doctors Radiologic Clinic, South Korea

${ }^{4}$ Dae Kyung Imaging Center, South Korea

${ }^{5}$ Department of Radiology, Daegu Catholic University

Medical Center, South Korea

${ }^{6}$ Department of Radiology, Pusan National University Hospital, South Korea

'Department of Radiology, J oint and Spine Hospital,

South Korea

*Corresponding author: Choo HJ , Department of Radiology, Inje University Pusan Paik Hospital, 47392, Busan, South Korea

Received: August 14, 2017; Accepted: September 07, 2017; Published: October 16, 2017

\section{Introduction}

Because enchondromas are the most common tumors of the hands, clinicians have a tendency to regard all hand bone tumors as enchondromas. However, a broad spectrum of bone tumors, including osteochondroma, osteoid osteoma, intraosseous lipoma, giant cell tumor, bizarre parosteal osteochondromatous proliferation, and even chondrosarcoma or osteosarcoma, involve the hand. Some bone tumors of the hands have atypical features compared to those involving other sites, causing delay of correct diagnosis and treatment [1]. Therefore, it is important to know the radiologic and clinical characteristics of bone tumors involving the hands to facilitate exact diagnosis and proper treatment. The purpose of this review is to support radiologists to diagnose the hand bone tumors by detailing the radiologic features, with emphasis on $\mathrm{CT}$ and MR findings.

\section{Benign Bone Tumors}

\section{Enchondroma}

Enchondroma is the most common bone tumor of the hand. This tumor consists of lobules of mature hyaline cartilage. Of enchondromas, $35 \%$ of arise in the hand, and enchondromas comprise $35 \%$ to $52.5 \%$ [1-3] of hand bone tumors [4]. The common sites in the hands are the proximal phalanges and metacarpals.

Enchondroma is usually asymptomatic, but often presents with pathologic fracture due to cortical thinning. Most

enchondromas are solitary, and they have an extremely low risk of malignant transformation, particularly in the

hand. However, patients with multiple enchondromatosis, such as Ollier's disease, have a higher risk (up to 25\%) of transformation into chondrosarcoma [5]. On radiography and CT, enchondroma appears as a central, well-defined osteolytic lesion with or without mineralized chondroid matrix, endosteal scalloping, and thinned cortex. The mineralization usually assumes the forms of dots, rings, and arcs. MRI demonstrates low to intermediate signal intensity on T1-weighted image and fluid-like very high signal intensity on T2weighted image. After contrast injection, enchondroma is enhanced in a typical way - linear or linear and globular enhancement along the margins of the hyaline cartilage lobules [6] (Figures 1,2). Curettage of the tumor and packing with autogenous cancellous bone, bone graft substitute, and/or allograft is the standard treatment [6-8].

\section{Enchondroma protuberans}

Enchondroma protuberans is a rare exophytic enchondroma that arises in the medullary canal. It usually develops in the phalanges or metacarpal bones of hands. On radiography, enchondroma
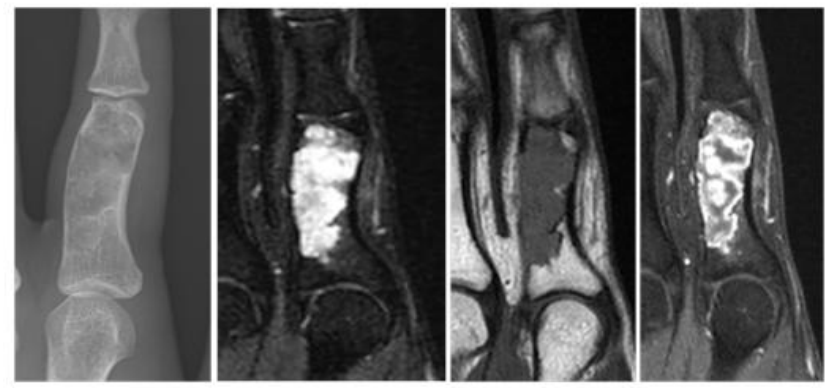

Figure 1: Enchondroma. A 16-year- old female with right $2^{\text {nd }}$ finger pain for 1 year. Anteroposterior radiograph of the hand shows an expansile radiolucent lesion at the $2^{\text {nd }}$ proximal phalanx $(A)$. It is very high signal intense on coronal fat-suppressed T2-weighted MR image (B) and intermediate signal intense on T1-weighted image (C). Contrast-enhanced T1-weighted image demonstrates the peripheral and globular enhancement of the tumor (D). 


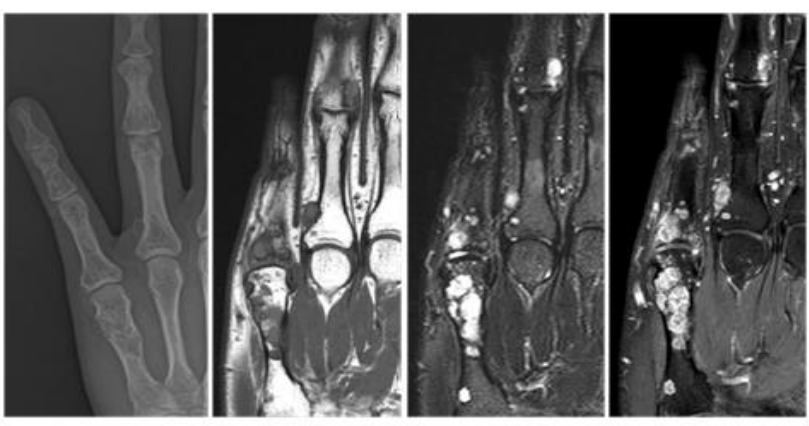

Figure 2: Enchondromatosis. A 31-year- old male with right hand pain for 2 months. Anteroposterior radiograph of the hand demonstrates multiple intraosseous and exophytic radiolucent lesions at the 5 th metacarpal bone and the $4^{\text {th }}$ and $5^{\text {th }}$ middle and proximal phalanges $(A)$. These lesions are demonstrated as intermediate signal intensity on coronal T1-weighted MR image (B) and high signal intensity on fat-suppressed T2-weighted image (C). After gadolinium injection, the lesions are shown as the peripheral globular enhancement (D).
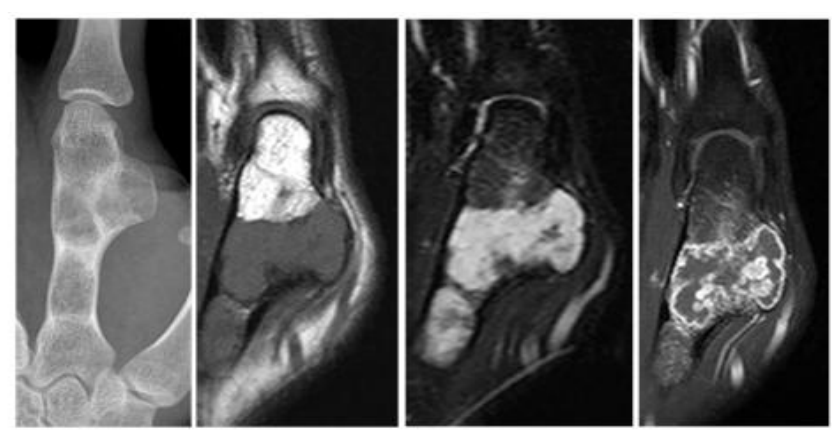

Figure 3: Enchondroma protuberans. A 15-year- old male with a palpable mass in hand for 3 years. Anteroposterior radiograph of the hand shows an exophytic mass continuous with an intramedullary osteolytic lesion in the $2^{\text {nd }}$ proximal phalanx $(A)$. The tumor is hypointense on T1-weighted image (B), hyperintense on T2-weighted MR image (C), and peripheral and nodular enhancement on contrast enhanced image (D).

protuberans typically appears as an exophytic protruding mass connected with an intramedullary geographic osteolytic lesion containing speckled calcification. CT and MR clearly delineate the connection between the intramedullary lesion and the exophytic protrusion (Figure 3). A combination of resection of the cartilage-containing protuberans and intramedullary curettage is recommended for treatment [4].

\section{Periosteal chondroma}

Periosteal chondroma, also known as juxtacortical chondroma, is a rare benign tumor that develops adjacent to the cortical surface. It is most often in patients younger than 30 years. About $22 \%$ of cases involve the fingers [9]. The typical radiographic features include pressure erosion at the cortical surface with remodeling and overhanging osseous margins (saucerization). Periosteal chondroma may have calcifications of the chondroid matrix combined with a sclerotic margin and a soft-dense mass. MR delineates a lobulated mass at the bone surface that demonstrates bright signal intensity on T2-weighted images, hypo- to iso- signal intensity on T1-weighted images with peripheral enhancement on contrast-enhanced images (Figure 4). Treatment of this lesion is a local excision [10-12].

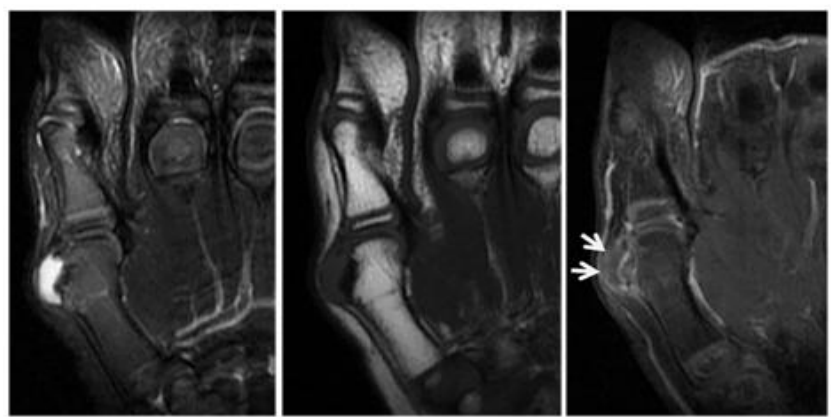

Figure 4: Periosteal chondroma. A 6-year- old male with a mass at the right thumb. Coronal fat-suppressed T2-weighted MR image shows a cortexbased periosteal lesion with high signal intensity with the adjacent cortical scalloping at the 1 st metacarpal head (A). It is shown as low signal intensity on T1-weighted image (B) and faint peripheral enhancement (arrow) on contrast-enhanced image (C).

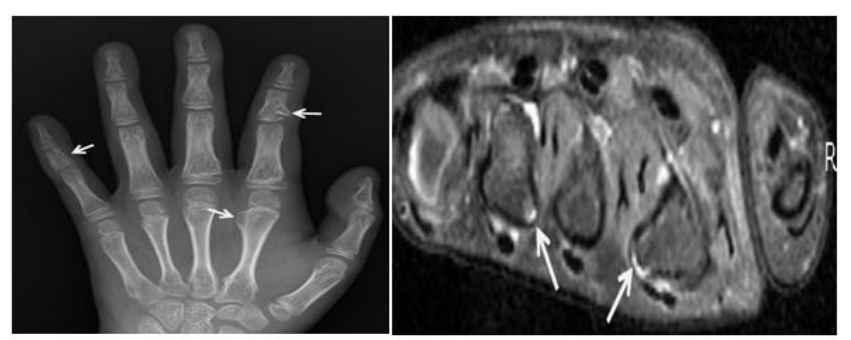

Figure 5: Hereditary multiple exostoses. An 8-year- old-girl with right hand pain. Anteroposterior radiograph of the right hand demonstrates multiple exostoses arising from the $2^{\text {nd }}$ and $5^{\text {th }}$ middle phalanges and the $2^{\text {nd }}$ metacarpal bone (arrows). The osteochondroma in the $2^{\text {nd }}$ middle phalanx results in a radial shortening of the $2^{\text {nd }}$ middle phalanx $(A)$. Axial fat-suppressed T2weighted MR image at the level of the metacarpal heads shows the exostoses with their cartilaginous caps (arrows) (B).

\section{Osteochondroma}

Osteochondroma is a benign, cartilage-capped protuberance of metaphysis or epiphysis. Osteochondromas may be solitary or multiple. Solitary osteochondromas are usually found in children and adolescents. About $4 \%$ of solitary osteochondromas involve the hands, most frequently the proximal phalanges $[13,14]$. Osteochondroma results from the separation of a fragment of the epiphyseal growth plate cartilage, which subsequently herniates through the periosteal bone cuff that normally surrounds the growth plate. Thus, the lesion is comprised of cortical and medullary bone with an overlying hyaline cartilage cap and demonstrates continuity with underlying parent bone cortex and medullary canal. All imaging can identify the cortical and marrow continuity between the exophytic mass and the parent bone. MR imaging typically shows the hyaline cartilage cap. Hereditary multiple exostosis is an autosomal dominant disorder that is characterized by multiple osteochondromas. It is usually found in early childhood and about $80 \%$ of cases involve the hands (Figure 5).

Malignant transformation is seen in $1 \%$ of solitary lesions, whereas it occurs in $3 \%$ to $5 \%$ of hereditary multiple exostoses [15]. Osteochondromas are usually asymptomatic but can present with pain or impaired motion if located near to a joint [16]. Surgery is indicated if lesions become symptomatic. Patients with hereditary multiple exostoses need continuous clinical and radiological 

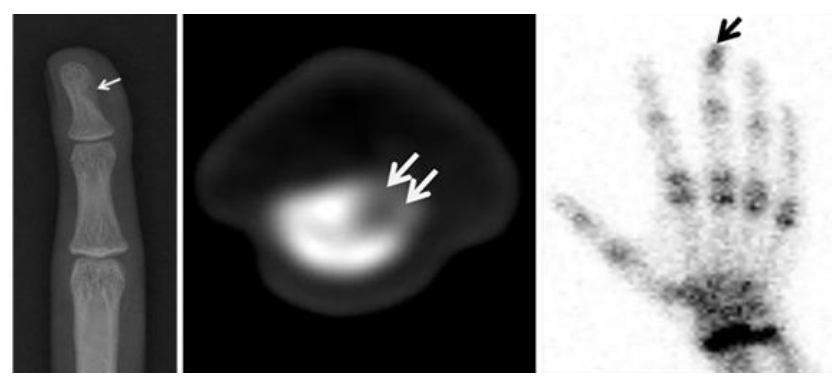

Figure 6: Osteoid osteoma. A 15-year- old male with swelling and pain in left $3^{\text {rd }}$ distal phalanx. Anteroposterior radiograph of the hand and axial CT demonstrate an osteolytic lesion (arrow) at the $3^{\text {rd }}$ distal phalanx without perilesional sclerosis, which is an unusual finding of osteoid osteoma $(A, B)$. But, it is displayed as high uptake on bone scan (arrow) like a typical osteoid osteoma (C).

surveillance to monitor for progression of deformities, shortening of the bone, or joint restriction $[15,17]$.

\section{Osteoid osteoma}

Osteoid osteoma is a benign osteoblastic tumor characterized by a nidus of less than $1.5 \mathrm{~cm}$ to $2 \mathrm{~cm}$ of osteoid bone in vascular tissue. It occurs commonly in boys and young men. The common locations are the femur and tibia, but about $10 \%$ of osteoid osteomas involve the hand, particularly the proximal phalanges. When the carpus is affected, the scaphoid is the most common site $[18,19]$. Typically, patients experience pain that worsens at night and is promptly relieved by salicylates. Radiography shows a radiolucent nidus accompanied by cortical thickening and reactive sclerosis. CT is useful to identify a calcified round or oval nidus. MR imaging depicts a nidus of variable signal intensity, depending on the amount of mineralization and the edema of the surrounding soft tissue and bone marrow. In radionuclide bone scans, osteoid osteomas show high uptake and sometimes a double density sign can be observed, which are characterized by intense scintigraphic activity in the central nidus with less intense accumulation in peripheral sclerotic bone (Figure 6). However, osteoid osteomas in the hands often present with atypical symptoms, such as monoarthritis or no pain. In this case, the radiologic features can be also atypical, including absence of reactive bone formation or a radiolucent nidus.

These atypical clinical and radiologic features may cause a delay in diagnosis and treatment $[19,20]$. Percutaneous radiofrequency ablation is a minimally invasive alternative to surgical treatment of osteoid osteoma, but a lesion in the hand is a relative contraindication to radiofrequency ablation. Surgery is the standard treatment when the histology of the lesion is in doubt, or if neurovascular structures are within $1.5 \mathrm{~cm}$. Cryotherapy, ethanol therapy, and imaging-guided excision are also considered as second-line therapies [21-24].

\section{Intraosseous lipoma}

Intraosseous lipoma is a benign bone tumor consisting of mature fat tissue and variable quantities of fibrous and vascular tissue. This lesion usually occurs in the 4 th and 5 th decades of life. Up to $70 \%$ of patients present with pain. Frequent locations of intraosseous lipomas are calcaneus, femur, and tibia. The hand is barely involved [25]. Milgram divided intraosseous lipomas into 3 stages according to histologic features: stage 1 , viable fat without necrosis; stage 2,

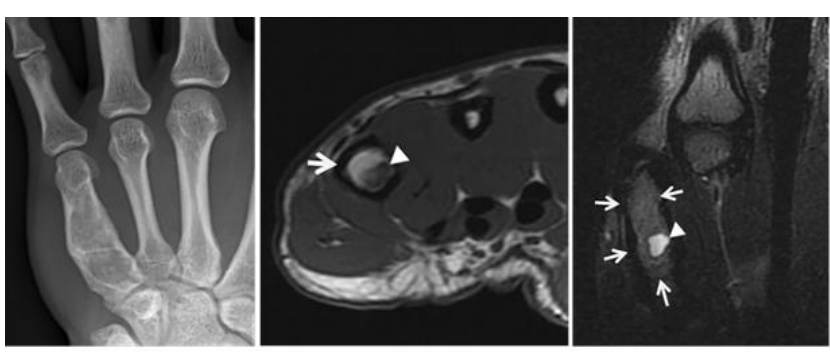

Figure 7: Intraosseous lipoma. A 21-year- old female with right hand pain. Anteroposterior radiograph of the hand shows an expansile radiolucent lesion at the $5^{\text {th }}$ metacarpal bone (A). On axial T1-weighted image, the lesion is shown as high signal intensity (arrow) with an intralesional low signal intense focus (arrowhead) (B). On coronal T2-weighted image, the main mass (arrows) is still demonstrated as high signal intensity, whereas an intralesional focus is high signal intense (arrowhead). These MR findings suggest an intraosseous lipoma with a focal cystic change (C).
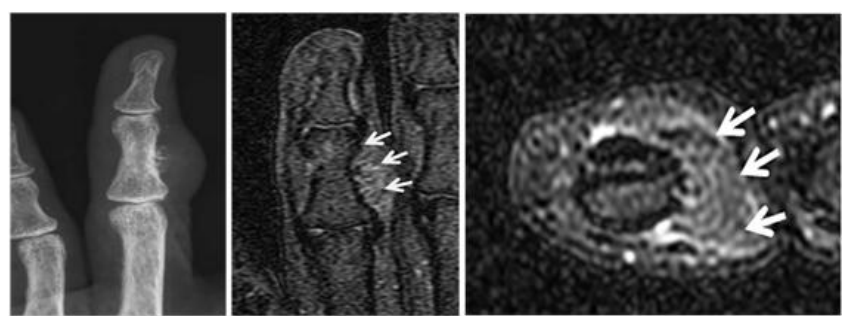

Figure 8: Parosteal lipoma. A 52-year- old female with a palpable mass in the $4^{\text {th }}$ finger. Anteroposterior radiograph of the hand shows a focal juxtacortical soft tissue swelling with the adjacent cortical protuberances at the $4^{\text {th }}$ middle phalanx (A). The extracortical mass is low signal intense on coronal fatsuppressed T2-weighted image (B) and no-enhanced (C) on axial contrastenhanced T1-weighted image like a subcutaneous fat (C).

viable fat with necrosis and dystrophic calcification; stage 3, extensive fat necrosis, cyst formation, calcification, and reactive new bone formation [26]. Radiologic features of the intraosseous lipoma also differ in accordance with these stages [27]. On CT, stage 1 lesions show resorption of bone trabeculae, fat attenuation, and bone expansion. Stage 2 lesions have areas of fat attenuation and calcification and stage 3 reactive ossification, calcification, and cyst formation. On MR imaging, stage 1 lesions have a fatty component. Stage 2 lesions show fat attenuation, cyst formation, and low signal intensity areas that are compatible with calcification (Figure 7), and stage 3 lesions show a thin peripheral rim of fat, central calcification, and a thick rim of surrounding sclerosis [28]. Symptomatic intraosseous lipomas are treated with curettage and bone graft placement [29].

\section{Parosteal lipoma}

Parosteal lipoma is a rare benign neoplasm characterized by mature adipose tissues arising in the periosteal membrane. It commonly involves the thigh adjacent to the femur or the upper extremity near the proximal radius. However, hand involvement is rare. When it occurs in the hand, the metacarpal or phalanges are the most common sites [30]. Patients with parosteal lipoma usually present a history of a slowly growing, painless, and immobile mass. On radiography, parosteal lipoma is seen as a juxtacortical radiolucent mass with changes to the surface bone such as cortical irregularity. CT and MR delineate productive changes of surface bone and juxtaosseous lipomatous components (Figure 8). Treatment of 

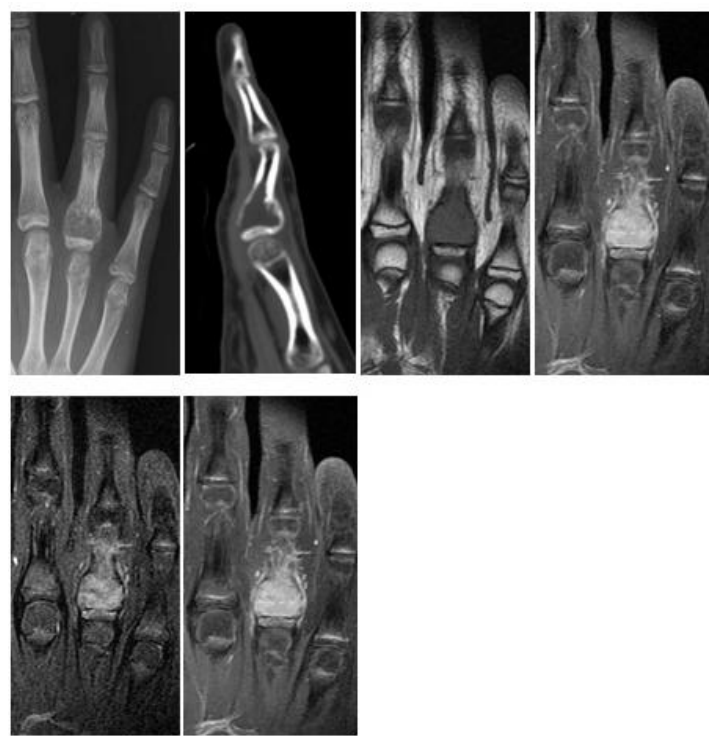

Figure 9: Giant cell tumor of the bone. A 13-year- old male with tenderness of the $4^{\text {th }}$ finger. Anteroposterior radiograph and sagittal reconstructed CT of the hand show an expansile osteolytic lesion at the $4^{\text {th }}$ proximal phalanx (A, $B$ ). It is shown as low T1 signal intensity (C), intermediate to high T2 signal intensity (D), and homogeneous enhancement (E).

parosteal lipoma is complete surgical resection [29].

\section{Giant cell tumor}

Giant cell tumor of the bone is a neoplastic process originating from undifferentiated mesenchymal cells of the bone marrow that is characterized by the presence of multinucleated giant cells [31]. Generally, giant cell tumor of the bone is benign, but approximately $2 \%$ to $5 \%$ may metastasize to lung [32]. It predominately occurs after skeletal maturation. From $2 \%$ to $5 \%$ occur in the hand, particularly in the metacarpals [33]. Patients present with nonspecific symptoms such as pain, swelling, or pathological fracture. Giant cell tumors arising in long tubular bones are eccentrically and epiphyseal located, while those arising from the hands are centrally located and more commonly associated with bony destruction and diaphyseal extension. Giant cell tumor of the hand bone has a higher postoperative recurrence rate than that arising in other sites [34]. CT demonstrates cortical thinning, pathologic fracture, periosteal reaction, and a degree of osseous expansile remodeling. On MR imaging, it is manifested as a relatively well-defined lesion with a low to intermediate signal intensity on all sequences, indicative of hemosiderin deposition (Figure 9) [35]. The usual treatment of giant cell tumor is a curettage. Local recurrence rate after this procedure ranges up to $40 \%[36,37]$.

\section{Aneurysmal bone cyst}

Aneurysmal bone cyst is a benign bone tumor that is characterized by septated blood filled spaces. It arises in situ or secondarily from preexisting benign or malignant bone tumors including giant cell tumor, osteoblastoma, chondroblastoma, or telangiectatic osteosarcoma. It occurs commonly in patients under 20 years old with open physis. The main symptom is pain of relatively acute onset. About $2 \%$ or $5 \%$ of aneurysmal bone cysts involve the hand, typically the metaphysis of metacarpals $[38,39]$. On radiography and
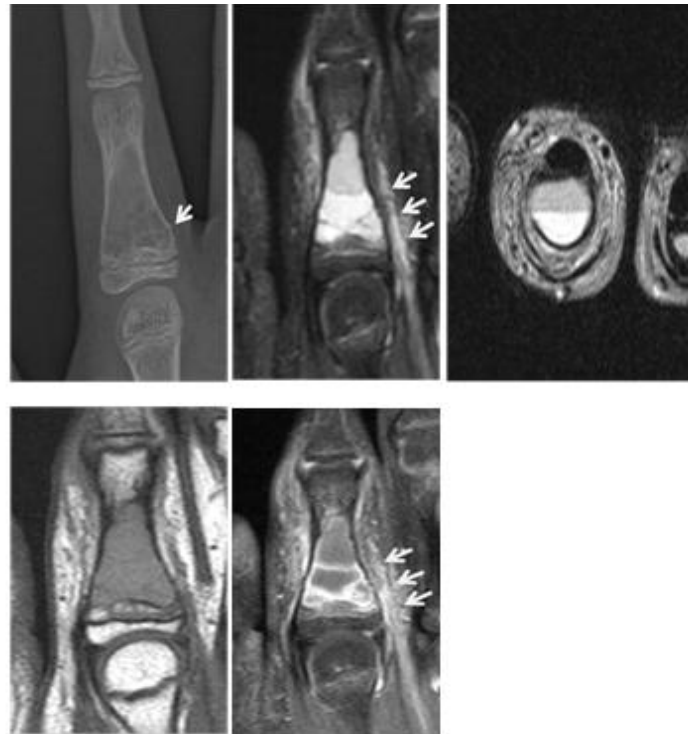

Figure 10: Aneurysmal bone cyst. An 11-year- old female with sudden left $2^{\text {nd }}$ finger pain. Anteroposterior radiograph of the hand shows an expansile radiolucent lesion with cortical disruption (arrow) at the $2^{\text {nd }}$ proximal phalanx (A). Coronal fat-suppressed and axial T2-weighted MR images show a multilocular cystic lesion containing fluid-fluid levels at the $2^{\text {nd }}$ proximal phalanx $(B, C)$. It is intermediate signal intense on T1-weighted image (D) and peripheral- and septal-enhanced on contrast-enhanced image $(E)$. The soft tissue edema (arrows) adjacent to the cortical break is identified $(B, E)$.
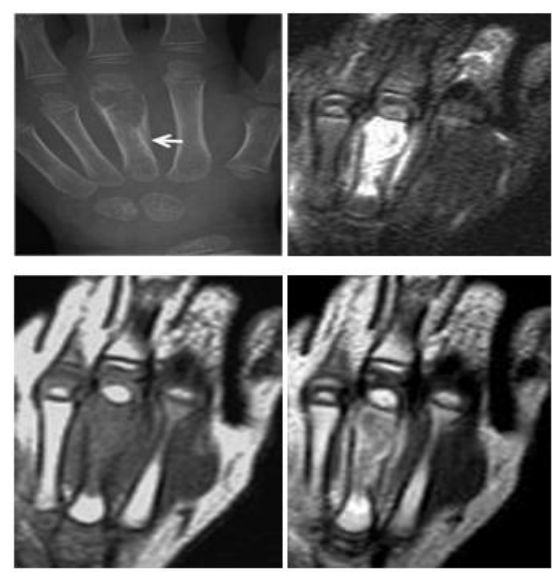

Figure 11: Eosinophilic granuloma. A 2-year- old female with swelling in hand. Anteroposterior radiograph of the hand shows an expansile radiolucent lesion with periosteal reaction (arrow) at the $3^{\text {rd }}$ metacarpal bone (A). Coronal fat-suppressed T2-weighted MR image shows a high signal intense mass lesion with edematous change of the surrounding soft tissue (B). The lesion is intermediate signal intense on T1-weighted image (C) and heterogeneously enhancement on contrast-enhanced image (D).

CT, aneurismal bone cysts appear as centrally-located, expansile, and osteolytic lesions. MR imaging reveals a multilocular cystic mass with contents of different signal intensities or fluid-fluid level in each chamber, representing different stages of blood by-products (Figure 10). Curettage is a standard treatment. Recurrence is common (up to $50 \%)[40]$.

\section{Eosinophilic granuloma}

Eosinophilic granuloma, as one of the 3 distinct clinical 


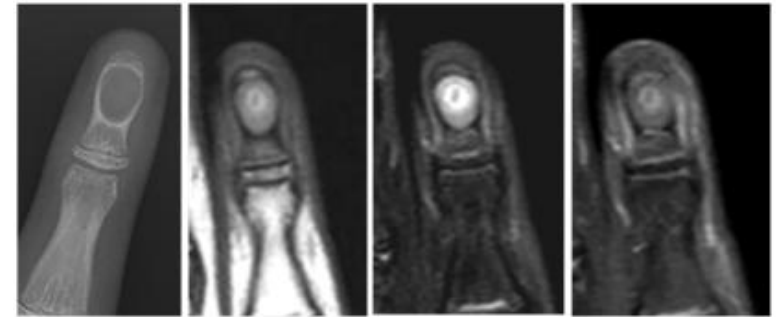

Figure 12: Intraosseous epidermal cyst. An 11-year- old female with a slowly growing mass in left $4^{\text {th }}$ distal phalanx. Anteroposterior radiograph of the hand shows a well-defined osteolytic lesion at the $4^{\text {th }}$ distal phalanx (A). The lesion is shown as intermediate signal intensity on coronal T1- and fat-suppressed T2-weighted MR images ( $B, C)$. In the middle of the lesion, high signal intense ring-like focus is identified on T1 and T2-weighted images, which suggests a laminated keratin. The lesion is not enhanced on coronal contrast-enhanced image (D).

syndromes of Langerhans cell histiocytosis, is a benign disease limited to bone or lung. It is most often found in children under 15 years old. Eosinophilic granuloma is usually asymptomatic, however, may be the site of fracture or the source of swelling and deformity. It usually involves skull, proximal femur and humerus, and rib. Multiple eosinophilic granulomas involve the small bones of the hands and feet with an incidence of $7 \%$, but solitary involvement of the hands is very rare [41,42]. On radiography and CT, eosinophilic granuloma shows cortical destruction and periosteal reaction. On MR imaging, it is usually manifested as low-, or intermediate signal intensity on T1weighted and high signal intensity on T2-weighted images (Figure 11). The treatment of the solitary bony lesion is a curettage of the affected site $[43,44]$.

\section{Intraosseous epidermal cyst}

Intraosseous epidermal cyst is an infrequent bony lesion, consisting of squamous epithelium and a laminated mass of keratin. It commonly involves the skull and the distal phalanges. It is most common in adults, especially manual workers. When it occurs in the hands, it presents with variable degrees of pain, swelling, nail deformity, and sometimes erythema. On radiography, intraosseous epidermal cyst appears as a well-defined, unilocular, osteolytic lesion with a sclerotic rim. Soft-tissue swelling, spotty calcifications, and bony fracture may be present. This lesion shows low signal intensity on T1-weighted images and variable signal intensity on T2weighted images, depending on the amount of keratin content. After gadolinium administration, the mass itself is not enhanced, but the surrounding tissue may be enhanced due to inflammatory reaction (Figure 12). The treatment of the phalangeal epidermoid cyst is a surgical excision with curettage. Bone grafting may be necessary for large defects [45,46].

\section{Bizarre parosteal osteochondromatous proliferation}

Bizarre parosteal osteochondromatous proliferation, also known as Nora's lesion, is an exophytic bone lesion originating from the cortical or periosteal surface and histologically characterized by a heterogeneous mixture of cartilage, bone, and fibrous tissue. It usually occurs in the hands, particularly phalanges and metacarpals, and is most common in the 3rd and 4th decade of life [47]. In one study, about $30 \%$ of cases had a history of previous trauma that ranged from 2 months to 3 years before presentation [48]. Thus,
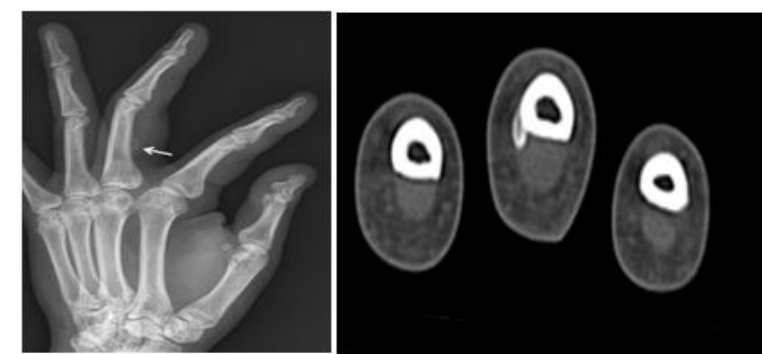

Figure 13: Bizarre parosteal osteochondromatous proliferation. A 51-yearold male with swelling in the left $3^{\text {rd }}$ finger. Oblique radiograph of the hand shows a focal extraosseous radiodense lesion (arrow) at the volo-radia aspect of the $3 \mathrm{rd}$ proximal phalanx (A). On axial CT, it is demonstrated as an exophytic osseous lesion attaching to the cortex of the proximal phalanx without continuity of the medulla (B).

the etiology of bizarre parosteal osteochondromatous proliferation is explained as a traumatic stimulus that causes subperiosteal hemorrhagic proliferation and progresses to serial florid reactive periostitis and bizarre parosteal osteochondromatous proliferation $[49,50]$. Patients typically present with a slow-growing, non-tender mass. Radiographically, bizarre parosteal osteochondromatous proliferation appears a well-defined, calcified, or ossified solid mass continuous with the underlying cortex, usually metaphysis. The size of lesion can range from 0.5 to $3.0 \mathrm{~cm}$ [13]. The absence of continuity with the medullar and lack of orientation away from the nearby physis are the differential features of bizarre parosteal osteochondromatous proliferation from osteochondroma.

$\mathrm{CT}$ and MR are useful in identifying the relationship of the osseous mass to the underlying cortex. The lesion is seen as a heterogeneous low signal intense mass on T1-weighted MR image with high signal intensity on T2-weighted image (Figure 13) [13]. Recommended treatment for bizarre parosteal osteochondromatous proliferation is surgical excision. Recurrence has been reported in more than $50 \%$ of cases [48].

\section{Malignant Bone Tumors}

\section{Chondrosarcoma}

Chondrosarcoma is the most common malignant bone tumor in the hand and about $1 \%$ of chondrosarcomas involve the hands [51]. Chondrosarcomas in the hands are common in the $6^{\text {th }}$ to $8^{\text {th }}$ decade of life [52], whereas the secondary chondrosarcomas of Ollier's disease occur at a younger age (around $3^{\text {rd }}$ to $4^{\text {th }}$ decade) [5]. The common site for the chondrosarcoma in the hand is the proximal phalanx. Clinically, pain is the most common symptom of chondrosarcoma, which generally considered suggesting malignancy. However, enchondromas in the hands also tend to become painful [52]. The radiologic findings between chondrosarcomas and enchondromas are overlapping as well. The suggestive radiologic signs of chondrosarcomas are cortical erosion, extension of the tumor into soft tissues, and irregularity or indistinctness of the surface of the tumor.

According to a study of dynamic MR imaging [53], delayed enhancement or absent enhancement can exclude a chondrosarcoma. Recently, peripheral cartilage islands surrounded by fat tissue have been reported as an exclusive sign of chondrosarcoma [54]. 

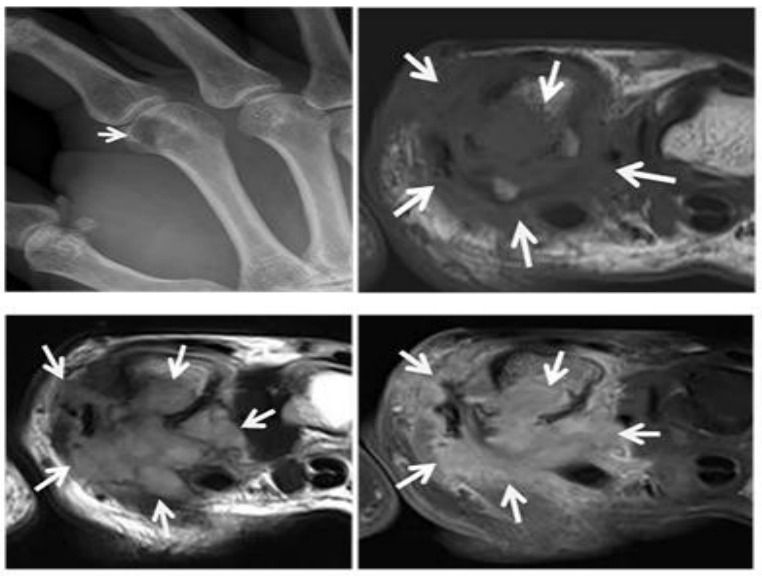

Figure 14: Osteosarcoma. A 54-year- old male with hand pain. Oblique radiograph of the hand shows an ill-defined radiolucent intramedullary lesion at the $2^{\text {nd }}$ metacarpal head (arrow) (A). Axial T1- and T2-weighted MR images show an intramedullary mass with aggressive extension to the adjacent soft tissue (arrows) (B,C). On contrast-enhanced T1-weighted image, the infiltrative lesion is well-enhanced and the margin of the enhanced lesion is indistinct and infiltrative, suggesting its aggressiveness (arrows) (D).

Treatment consists of the wide en-bloc excision or amputation. Neither chemotherapy nor radiotherapy is effective [52].

\section{Osteosarcoma}

Although osteosarcomas are the most common primary malignant bone tumor, only $0.18 \%$ of them occur in the hands. When they occur at the hands, the proximal phalanges and metacarpals are the most common sites [55]. Many cases of osteosarcomas of the hands are secondary type, caused by radiation or Paget's disease.

Therefore, osteosarcomas in hands are seen between 40 and 70 years of age patients, whereas primary osteosarcomas appear in the $2^{\text {nd }}$ and $3^{\text {rd }}$ decade. Histologically, osteosarcomas arising in the hands are usually well-differentiated [55,56]. Clinical manifestations include pain and swelling, restriction of motion, warmth, and pyrexia. On radiography, osteosarcoma appears as an ill-defined lesion with moth-eaten bone destruction and periosteal reaction with various ossifications. MR imaging is an important technique for local staging and determination of appropriate surgical management. Signal intensity of osteosarcomas on MR depends on the presence of mineralization. Non-mineralized tumors show high signal intensity on T2-weighted images and mineralized tumors show low signal intensity (Figure 14). Neoadjuvant or adjuvant chemotherapy is the recommended treatment in addition to surgical excision of osteosarcoma [23].

\section{Bone metastasis}

Bone metastasis of the hands is very rare and comprises about $0.1 \%$ of all bony metastasis [57]. However, metastasis into the hands can be the first clinical sign of a malignancy. The most common sites of primary cancer are lung, kidney, and breast. The distal phalanges are the most common sites for hand bone metastasis, followed by the metacarpals and proximal phalanges [36]. These lesions usually present as a painful, swollen, erythematous extremity stimulating infection, thus delay in diagnosis is common. On radiography, metastatic disease usually appears as a purely osteolytic destructive

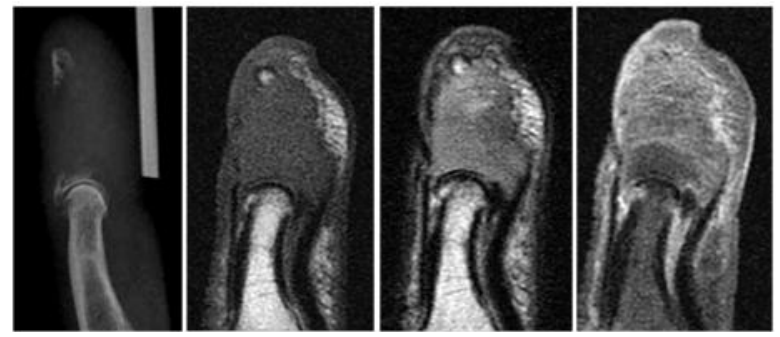

Figure 15: Bone metastasis from lung cancer. A 71-year- old man with the $4^{\text {th }}$ distal phalanx pain for 1 month. Lateral radiograph of the hand shows a destructive osteolytic lesion at the $4^{\text {th }}$ distal phalanx (A). The destructive lesion is shown as low signal intensity on sagittal T1-weighted MR image (B), slightly high signal intensity on T2-weighted image (C), and heterogeneous enhancement on contrast-enhanced T1-weighted image (D).

lesion (Figure 15), however, it can be sclerotic, as in cases of metastasis from prostate cancer, or mixed, as in gastrointestinal malignancy. Because metastasis to the hands generally accompanies widespread disease, the prognosis is poor and most patients have a life expectancy of 6 months [36]. As an exception, renal cell carcinoma with a solitary hand metastasis has been reported to have excellent survival rate with nephrectomy and wide resection of the metastatic lesion or amputation [58]. Various methods of treatment are available, according to the status of the patients, localization of the lesion, and primary cancer site. Amputation, radiotherapy, curettage, cementation, chemotherapy, and wide excision are the forms of treatment used most often [59].

\section{Conclusion}

Enchondromas are the most common bone tumors in the hands, however, a broad spectrum of bone tumors affect the hands. A general knowledge of the main imaging features of the various bone tumors of hands can facilitate exact diagnosis of the disease.

\section{Acknowledgment}

This material is based upon work supported by the Ministry of Trade, Industry \&amp; Energy (MOTIE, Korea) under industrial Technology Innovation Program. NO. 10062728.

\section{References}

1. Besser E, Roessner A, Brug E, Erlemann R, Timm C, Grundmann E. Bone tumors of the hand. Arch Orthop Trauma Surg. 1987; 106: 241-247.

2. Bickels J, Wittig JC, Kollender Y, Kellar-Graney K, Mansour KL, Meller I, et al. Enchondromas of the hand: treatment with curettage and cemented internal fixation. J Hand Surg Am. 2002; 27: 870-875.

3. Farzan M, Ahangar P, Mazoochy $H$, Ardakani MV. Osseous tumors of the hand. Arch Bone Jt Surg. 2013; 1: 68-73.

4. An YY, Kim JY, Ahn MI, Kang YK, Choi HJ. Enchondroma protuberans of the hand. AJR Am J Roentgenol. 2008; 190: 40-44.

5. Kosaki N, Yabe H, Anazawa U, Morioka H, Mukai M, Toyama Y. Bilateral multiple malignant transformation of Ollier's disease. Skeletal Radiol. 2005; 34: 477-484.

6. Payne WT, Merrell G. Benign bony and soft tissue tumors of the hand. J Hand Surg Am. 2010; 35: 1901-1910.

7. Campbell DA, Millner PA, Dreghorn CR. Primary bone tumours of the hand and wrist. J Hand Surg Am. 1995; 20: 5-7.

8. Plate AM, Lee SJ, Steiner G, Posner MA. Tumorlike lesions and benign tumors of the hand and wrist. J Am Acad Orthop Surg. 2003; 11: 129-141. 
9. deSantos LA, Spjut HJ. Periosteal chondroma: a radiographic spectrum Skeletal Radiol. 1981; 6: 15-20.

10. Woertler K, Blasius S, Brinkschmidt C, Hillmann A, Link TM, Heindel W. Periosteal chondroma: MR characteristics. J Comput Assist Tomogr. 2001 25: $425-430$

11. Robinson P, White LM, Sundaram M, Kandel R, Wunder J, McDonald DJ, et al. Periosteal chondroid tumors. AJR Am J Roentgenol. 2001; 177: 11831188.

12. Brien EW, Mirra JM, Luck JV. Benign and malignant cartilage tumors of bone and joint: their anatomic and theoretical basis with an emphasis on radiology, pathology and clinical biology. II. Juxtacortical cartilage tumors. Skeletal Radiol. 1999; 28: 1-20

13. James SL, Davies AM. Surface lesions of the bones of the hand. Eur Radiol. 2006; 16: 108-123.

14. Moore JR, Curtis RM, Wilgis EF. Osteocartilaginous lesions of the digits in children: an experience with 10 cases. J Hand Surg Am. 1983; 8: 309-315.

15. Murphey MD, Choi JJ, Kransdorf MJ, Flemming DJ, Gannon FH. Imaging of osteochondroma: variants and complications with radiologic-pathologic correlation. Radiographics. 2000; 20: 1407-1434.

16. van Alphen JC, te Slaa RL, Eulderink F, Obermann WR. Solitary osteochondroma of the scaphoid: a case report. J Hand Surg Am. 1996; 21 423-425.

17. Koshi H, Shinozaki T, Hosokawa T, Yanagawa T, Takagishi K. Solitary osteochondroma of the trapezium: case report. J Hand Surg Am. 2011; 36: 428-431.

18. Ambrosia JM, Wold LE, Amadio PC. Osteoid osteoma of the hand and wrist. J Hand Surg Am. 1987; 12: 794-800.

19. Marcuzzi A, Acciaro AL, Landi A. Osteoid osteoma of the hand and wrist. J Hand Surg Br. 2002; 27: 440-443.

20. Burger IM, McCarthy EF. Phalangeal osteoid osteomas in the hand: a diagnostic problem. Clin Orthop Relat Res. 2004; 427: 198-203.

21. Chai JW, Hong SH, Choi JY, Koh YH, Lee JW, Choi JA, et al. Radiologic diagnosis of osteoid osteoma: from simple to challenging findings. Radiographics. 2010; 30: 737-749.

22. Radcliffe SN, Walsh HJ, Carty H. Osteoid osteoma: the difficult diagnosis. Eur J Radiol. 1998; 28: 67-79.

23. Maples WJ, Buskirk SJ. Multimodality treatment of upper extremity bone and soft tissue sarcomas. Hand Clin. 2004; 20: 221-225.

24. Motamedi D, Learch TJ, Ishimitsu DN, Motamedi K, Katz MD, Brien EW, et al. Thermal ablation of osteoid osteoma: overview and step-by- step guide. Radiographics. 2009; 29: 2127-2141.

25. Bower G, Hosny S, Umarji SI. Intraosseous lipoma of the scaphoid. J Hand Surg Eur Vol. 2012; 37: 799-800.

26. Milgram JW. Intraosseous lipomas: radiologic and pathologic manifestations. Radiology. 1988; 167: 155-160.

27. Campbell RS, Grainger AJ, Mangham DC, Beggs I, Teh J, Davies AM Intraosseous lipoma: report of 35 new cases and a review of the literature. Skeletal Radiol. 2003; 32: 209-222.

28. Propeck T, Bullard MA, Lin J, Doi K, Martel W. Radiologic-pathologic correlation of intraosseous lipomas. AJR Am J Roentgenol. 2000; 175: 673678.

29. Murphey MD, Carroll JF, Flemming DJ, Pope TL, Gannon FH, Kransdorf MJ. From the Archives of the AFIP Benign Musculoskeletal Lipomatous Lesions. Radiographics. 2004; 24: 1433-1466.

30. Yamamoto T, Marui T, Mizuno K. Parosteal lipoma of the distal phalanx: a case report and review of the literature. Clin Orthop Relat Res. 2001; 389: 181-184.

31. Wülling M, Engels C, Jesse N, Werner M, Delling G, Kaiser E. The nature of giant cell tumor of bone. J Cancer Res Clin Oncol. 2001; 127: 467-474.
32. Resnick D, Kransdorf MJ. Bone and joint imaging. $3^{\text {rd }}$ edition. Philadelphia: Elsevier Saunders. 2004

33. Athanasian EA, Wold LE, Amadio PC. Amadio. Giant cell tumors of the bones of the hand. J Hand Surg Am. 1997; 22: 91-98.

34. James SL, Davies AM. Giant-cell tumours of bone of the hand and wrist: a review of imaging findings and differential diagnoses. Eur Radiol. 2005; 15 : 1855-1866

35. Aoki J, Tanikawa H, Ishii K, Seo GS, Karakida O, Sone S, et al. MR findings indicative of hemosiderin in giant-cell tumor of bone: frequency, cause, and diagnostic significance. AJR Am J Roentgenol. 1996; 166: 145-148.

36. Hsu CS, Hentz VR, Yao J. Tumours of the hand. Lancet Oncol. 2007; 8 : 157-166.

37. Balke M, Schremper L, Gebert C, Ahrens H, Streitbuerger A, Koehler G, et al. Giant cell tumor of bone: treatment and outcome of 214 cases. J Cancer Res Clin Oncol. 2008; 134: 969-978.

38. Tillman BP, Dahlin DC, Lipscomb PR, Stewart JR. Aneurysmal bone cyst: an analysis of ninety-five cases. Mayo Clin Proc. 1968; 43: 478-495.

39. Johnston AD. Aneurysmal bone cyst of the hand. Hand Clin. 1987; 3: 299310.

40. Vergel AM, Bond JR, Shives TC, McLeod RA, Unni KK. Aneurysmal bone cyst. A clinicopathologic study of 238 cases. Cancer. 1992; 69: 2921-2931.

41. Miller MA, Williams WW. Eosinophilic granuloma of the hand. J Hand Surg Br. 1993; 18: 742-745.

42. Demiral AN, Ozdemir O, Coskunol E, Bacakoglu A, Cevikol C, Basdemir G. Solitary eosinophilic granuloma of the third metacarpal at pediatric age. Pediatr Hematol Oncol. 2003; 20: 589-595.

43. Hoover KB, Rosenthal DI, Mankin H. Langerhans cell histiocytosis. Skeletal Radiol. 2007; 36: 95-104

44. Stull MA, Kransdorf MJ, Devaney KO. Langerhans cell histiocytosis of bone Radiographics. 1992; 12: 801-823.

45. McGraw P, Bonvento B, Moholkar K. Phalangeal intraosseous epidermoid cyst. Acta Orthop Belg. 2004; 70: 365-367.

46. Nakajo M1, Ohkubo K, Nandate T, Nagano $Y$, Shirahama H, Nakajo M Intraosseous epidermal cyst of the distal phalanx of the thumb: radiographic and magnetic resonance imaging findings. Radiat Med. 2005; 23: 128-132.

47. Nora FE, Dahlin DC, Beabout JW. Bizarre parosteal osteochondromatous proliferations of the hands and feet. Am J Surg Pathol. 1983; 7: 245-750.

48. Meneses MF, Unni KK, Swee RG. Bizarre parosteal osteochondromatous proliferation of bone (Nora\&\#39;s lesion). Am J Surg Pathol. 1993; 17: 691697.

49. Yuen M, Friedman L, Orr W, Cockshott WP. Proliferative periosteal processes of phalanges: a unitary hypothesis. Skeletal Radiol. 1992; 21: 301-303.

50. Sundaram M, Wang L, Rotman M, Howard R, Saboeiro AP. Florid reactive periostitis and bizarre parosteal osteochondromatous proliferation: prebiopsy imaging evolution, treatment and outcome. Skeletal Radiol. 2001; 30: 192-198.

51. Nigrisoli M, Ferraro A, De Cristofaro R, Picci P. Chondrosarcoma of the hand and foot. Chir Organi Mov. 1990; 75: 315-323.

52. Ogose A, Unni KK, Swee RG, May GK, Rowland CM, Sim FH. Chondrosarcoma of small bones of the hands and feet. Cancer. 1997; 80: 50-59.

53. Geirnaerdt MJ, Bloem JL, Eulderink F, Hogendoorn PC, Taminiau AH Cartilaginous tumors: correlation of gadolinium-enhanced MR imaging and histopathologic findings. Radiology. 1993; 186: 813-817.

54. Vanel D, Kreshak J, Larousserie F, Alberghini M, Mirra J, De Paolis M, et al Enchondroma vs. chondrosarcoma: A simple, easy-to- use, new magnetic resonance sign. Eur J Radiol. 2013; 82: 2154-2160.

55. Okada K, Wold LE, Beabout JW, Shives TC. Osteosarcoma of the hand: a clinicopathologic study of 12 cases. Cancer. 1993; 72: 719-725. 
56. Mathov SH1, Bougie JD, Awad S. Osteosarcoma of the hand: a rare case for radiographic appearance, location, and age. J Manipulative Physiol Ther. 2008; 31: 164-167.

57. Kerin R. The hand in metastatic disease. J Hand Surg Am. 1987; 12: 77-83.

58. Jung ST, Ghert MA, Harrelson JM, Scully SP. Treatment of osseous metastases in patients with renal cell carcinoma. Clin Orthop Relat Res. 2003; 409: 223-231.

59. Flynn CJ, Danjoux C, Wong J, Christakis M, Rubenstein J, Yee A, et al. Two cases of acrometastasis to the hands and review of the literature. Curr Oncol. 2008; 15: 51-58.
Austin J Radiol - Volume 4 Issue 3 - 2017

ISSN : 2473-0637 | www.austinpublishinggroup.com

Choo et al. () All rights are reserved
Citation: Lee SJ, Choo HJ, Heo YJ, SW Kim, Cho KH, Suh KJ, et al. Bone Tumors of the Hands: Focus on CT and MR Findings. Austin J Radiol. 2017; 4(3): 1074. 